\title{
Drawbacks of Social Impacts Assessment in Brazil: Is It Time for a New Approach?
}

\author{
Marcelo Montaño $^{1^{*}}$ (1) , Renata Utsunomiya ${ }^{2}$, Marcelo Marini Pereira de Souza ${ }^{3}$ \\ ${ }^{1}$ Studies of Environmental Policy, Sao Carlos School of Engineering, University of Sao Paulo, Sao Paulo, Brazil \\ ${ }^{2}$ Institute of Energy and Environment, University of Sao Paulo, Sao Paulo, Brazil \\ ${ }^{3}$ Studies of Environmental Sciences and Policies, Ribeirao Preto Faculty of Philosophy Sciences and Letters, University of Sao \\ Paulo, Ribeirao Preto, Brazil \\ Email: *minduim@sc.usp.br
}

How to cite this paper: Montaño, M., Utsunomiya, R. and de Souza, M.M.P. (2021) Drawbacks of Social Impacts Assessment in Brazil: Is It Time for a New Approach? Journal of Environmental Protection, 12, 10861101.

https://doi.org/10.4236/jep.2021.1212064

Received: October 22, 2021

Accepted: December 11, 2021

Published: December 14, 2021

Copyright (c) 2021 by author(s) and Scientific Research Publishing Inc. This work is licensed under the Creative Commons Attribution International License (CC BY 4.0).

http://creativecommons.org/licenses/by/4.0/

\begin{abstract}
Environmental Impact Assessment (EIA) has shown a progressive improvement in addressing environmental impacts worldwide. However, EIA practice in Brazil and in other developing countries has been recognized as insufficient to deal with relevant issues related to the implementation of projects. One of the reasons found in the literature is related to the difficulties to integrate the biophysical environment and social issues within the decision-making process. In this paper, the practice of EIA in Brazil is analyzed in order to verify the relevance that social, cultural and economic impacts have been given for the acceptability of development projects. Firstly, a quality review of 23 randomly selected Environmental Impact Statements (EIS) from federal and state levels were checked in order to verify the range of social issues that have been encompassed. Secondly, seven EIS were scrutinized to check the adherence to international principles of Social Impact Assessment (SIA) best practices and guidelines applied to this instrument. The outcomes reveal a gap between the legal and empirical frameworks that describe the practice of SIA in Brazil and the main principles and guidelines for best practice in SIA. The paper concludes for the need to improve the effectiveness in the assessment of the social dimensions of environmental impacts in order to better inform the decisions. Also, the practice of EIA Brazil would benefit from guidelines for SIA and its integration to the EIA process.
\end{abstract}

\section{Keywords}

Impact Assessment, Social Impacts, Effectiveness 


\section{Introduction}

Environmental Impact Assessment (EIA) has been progressively contributing to better address the environmental impacts that are likely to be caused by development projects, as a result of the consolidation of EIA systems worldwide, theory development and new/innovative approaches [1] [2] [3].

Concerning the evaluation of social impacts and their integration in decisionmaking, [4] [5] [6] and [7] warn about the mismatch between the theoretic potential and what is actually achieved by the practice of Social Impact Assessment (SIA), mainly because of the lack of legal regulations and the absence of consolidated methodological guidelines. According to [8] (p. 34), the current concept of SIA can be presented as "the process of analyzing, monitoring and managing the social consequences of planned interventions and, by logical extension, the social dimensions of development in general'.

According to [5], SIA would be a kind of an "orphan" amongst other instruments of impact assessment, therefore narrowing its scope and also in the goals initially established for the instrument. Basically, the social impacts have been described in terms of demographic and socioeconomic indicators, with no substantial effect to the decision-making. Therefore, impact assessments have limited access to the full potential of SIA "to identify and clarify the cause(s) of environmental and natural resources conflicts" and to "possibly enable some avoidance or early mitigation" [9] (p. 293).

Hence, EIA has not benefited from the capacity of SIA to anticipate negative effects and the subsequent conflicts that may arise between different interest groups. Historically, EIA decisions have been subject to public/judicial challenges and court decisions that-at the end of the day-can obstruct the development of new projects but, on another hand, contribute to significant improvements in the whole process of EIA [10] [11] [12].

Thus, the present paper analyzes the practice of EIA in Brazil in order to verify the relevance that social, cultural and economic impacts have been given in decision-making, considering the acceptability of development projects.

\section{Background}

Given the backdrop to the application of impact assessment instruments, wherein is usual to put in antagonistic sides economic growth and environmental quality, the decision-making process is characterized by the emergence of a conflict arena in which the conceptual aspects of the decision to be taken (which sets the "optimal") are often shadowed by the pragmatic ones (where prevails what is "possible").

In this sense, it is remembered by [13] that it is "patently illusionary, or worse, to expect IA instruments to produce radical transformations where their framing of policy issues is strongly curtailed by institutional factors". Nevertheless, "perhaps theoreticians also need to reflect more critically on the assumptions underpinning IA, for it may be that theoretical simplifications are producing unrealis- 
tic expectations about precisely what can be achieved in practice through the use of IA" (p. 93).

[14] verified empirically that the main factor that stimulates the preparation of an impact assessment is the necessity to accomplish legal requirements. According to their analysis, decision makers are more concerned in not to face legal constraints than to properly achieve the full potential of impact assessment in decision-making. It is therefore essential to the practice of impact assessment that the legal requirements, which will describe the framework to the application of IA instruments, have been shaped by principles and guidelines aligned with the best practices to each instrument.

[15] is critical on the establishment of social impacts lists to guide the evaluations, even though he considers important as a reference element for the studies performed. According to this author, "it is clear that there are wide discrepancies about what constitutes social impacts" (p. 188). Anyway, the existence of guidelines to the practice of social impacts assessment, seems to be a very important condition for the increasing the efficiency of impact assessments.

Since the approval of the US National Environmental Policy Act (NEPA) in 1969, a legal landmark to Environmental Impact Assessment in the USA that has been used as a reference to EIA in other countries, an instrumental referential is established for the impacts assessment which includes the "human environment". However, there is a controversy in relation to the accomplishment of its further regulations for SIA, for example, the initial Council on Environmental Quality (CEQ) guidelines of 1973 and the final CEQ guidelines of 1978 did not formally mention "social impact assessment"; only the revised EIA guidelines of 1986 brings the term "socioeconomic impacts".

According to [5], in the beginning of the NEPA's application, the lack of an explicit social demand resulted in a superficial insertion of the social impacts in the studies performed by firms and advisory companies contracted by the American federal agencies-engineers and architects who worked in the creation of environmental studies decreased all the social universe to the description of demographic and socioeconomic markers, without many worries with the impact forecasts on the populations and communities. To make it worse, "no funds were available for the research financing to assemble the findings about social impacts uncovered in these assessments" (p. 7), which helped for the low "prestige" of SIA among the impact assessment instrument.

According to [16], the commitment to include the socioeconomic environment in impact studies was not present in NEPA-and for some, is yet to be verified-focusing in the physical and biotic environment. The social variables would have been included following a series of court decisions, to trade off environmental impact against economic and social factors in a systematic balancing analysis.

Social Impact Assessment is strongly related to other impact assessment instruments, though according to [17] "SIA should not be understood only as the task of predicting social impacts in an impact assessment process" (p. 6). It in- 
cludes the process of analyzing, monitoring and managing the intended and unintended social consequences, both positive and negative, of planned interventions and the social changes derived from those interventions, with the main purpose of bringing about a more sustainable and equitable biophysical and human environment.

\section{Principles and Guidelines for SIA}

The need for more accurate and up to date guidance for the practice of SIA, namely to guide the scope and methodological procedures to be applied, can be recognized considering the historic process found in the 1990's and 2000's decades. The delivery of the Guidelines and Principles for Social Impact Assessment (G\&P SIA) in 1994/1995, by the Interorganizational Committee on Guidelines and Principles for Social Impact Assessment, may be considered as one of the main landmarks to SIA, mainly due to its alignment with the NEPA context in the USA, even though almost twenty-five years have gone between the promulgation of NEPA and the publication of G\&P SIA. Curiously, [5] states that this document was not successful as a guiding element for both the research and the practice and SIA, despite the apparent approval by the academic community ${ }^{1}$.

In 2003, two other guidance documents were disclosed, aiming to support the development of SIA practice-the US Principles and Guidelines (US 2003) and the International Principles and Guidelines (Intern 2003), prepared over a five year period as an official project of the International Association for Impact Assessment-IAIA.

Tables 1-3 feature a synthesis of the principles for the mentioned documents.

Following the publication of these documents, the international community involved with the subject started a discussion on how each one of the documents covered the critics created for SIA and helped to develop the discussions on the instrument. According to [19] (p. 13), "while the International Principles [Intern 2003] is someway incomplete, it presents a very different picture of SIA to that presented in the US Principles and Guidelines [US 2003]. While the document, too, is inadequate and is unlikely to fulfill all of the listed objectives, it at least does address the criticisms made on the original G\&P [G\&P 95] and also the various critiques of SIA in general. It genuinely does attempt to consider a broad range of social issues and to extend from the project level to the policy lever".

[19] also compared both documents published in the same year and concluded that US 2003 brings an approach to SIA that might be pointed as positivist and technocratic and criticized because it was created by a team comprised of 12 people. The approach announced by Intern 2003 is considered as "democratic, participative and constructivist", and supposedly it would have more credibility due to its creation by an international commission, which the aforementioned author himself was a part of.

${ }^{1}$ According to [5] and [19], this document was originally published in 1994 by the US Department of Commerce, NOAA and the US National Marine Fisheries Service as a technical memorandum, and reprinted in Impact Assessment (1994) and in EIA Review (1995) journals. 
Table 1. Principles for SIA, according to G\&P SIA ([18]).

1) Involve the diverse public-identify and involve all potentially affected groups and individuals.

2) Analyse impact equity-who will win and who will lose, and emphasize vulnerability of under-represented groups.

3) Focus the assessment-deal with issues and public concerns that really count.

4) Identify methods and assumptions and define impact significance.

5) Provide feedback on social impacts to project planners-identify problems that could be solved with changes in the project or alternatives.

6) Use SIA practitioners-trained social scientists employing Social Science methods will provide the best results.

7) Establish monitoring and mitigation program—-manage uncertainty.

8) Identify appropriate data sources.

9) Plan for gaps in data.

Source: [18].

Table 2. Principles and guidelines for SIA, according to US 2003 ([20]).

1) Achieve extensive understanding of local and regional settings to be affected

a-Identify and describe interested and affected stakeholders and other parties

b-Develop baseline information of local and regional communities

2) Focus on key elements of human environment

a-Identify the key social and cultural aspects related to the action or policy from the community and stakeholder profiles

b-Select social and cultural variables that measure and explain the issues identified

3) Identify methodologies of research, hypothesis and relevances

a-Methodologies must have holistic scope, i.e., they must describe all aspects of the social impacts related to intervention or politics

b-Methodologies must describe cumulative social effects related to intervention or politics

c-To ensure that methodologies and forecasts are clear and replicable

$\mathrm{d}$-To select manners and level of data collect analysis appropriate for the importance of the intervention or politics

4) Provide quality information for use in decision-making

a-To collect information, whether quantitative and qualitative, about social, economic and cultural aspects which are sufficient and useful to describe and rationally analyze the alternatives for the intervention.

$\mathrm{b}-$ To ensure that the data collection, methodologies and analysis models are scientifically robust

c-To ensure the integrity of the collected information

\section{5) To ensure that any subject related to the environmental justice is fully described and analyzed}

a-To ensure that the research methods, data and analysis consider population and underrepresented vulnerable actors

b-To consider the distribution of all impacts (whether they are social, economic, air quality, noise or potential health effect) in different social groups, including ethnic and racial and migratory groups

6) To undertake assessment/monitoring and mitigation

a-To establish assessment mechanisms and monitoring of interventions, politics or programs

$\mathrm{b}-$ Where the impact mitigation is required, provide planning and mechanism to ensure the mitigation efficiency.

c-Identification of gaps in data and planning for the fulfillment of required data

Source: adapted from [20]. 
Table 3. Principles for SIA practice, in accordance with International Principles for Social Impact Assessment 2003 ([21]).

1) The equitable consideration must be the main element of the impact assessment and development planning.

2) Most part of the intervention social impacts may be foreseen.

3) Planned interventions may be changed to decrease the negative impacts and highlight the positive ones.

4) SIA must be the integral part of the development planning process, in all stages, from the beginning to the final audiences.

5) A focus in the sustainable social development must be in place, with SIA helping in the determination of the best development options-SIA (and EIA) have more to offer than just being the decider between economical benefits and social costs.

6) In all interventions and assessments, paths for the construction of social and human capital of local communities and strengthening of democratic processes must be developed.

7) All interventions and assessments, especially those where there are unavoidable impacts, must be investigated in a manner to change affect people into beneficiaries.

8) SIA must properly consider the alternatives of any intervention, mainly where there are unavoidable impacts.

9) All considerations must be done for the potential mitigation measures of environmental and social impacts, even when the impacted communities approve the intervention and where they may be beneficiaries.

10) In any assessment, the local knowledgement and experience must be incorporated, as well the acknowledgment of different local cultural values.

11) The use of violence, stalking, intimidation or unfair forces related to assessment or intervention implementation must not be employed.

12) Development processes that violate the human rights of any sector of the society must not be accepted.

Source: adapted from [21].

Maybe the differences between the documents should be understood from the context they were created, it would explain the "technocratic" aspect in relation to the US 2003 content, in view of strict relation with goals of the assess-andapprove type of most of the NEPA-based EIA instruments, that have an amazing influence in most of the EIA systems around the world. By its turn, aiming to present a set of guidances supported by the main international association of researchers and practitioners, the document Internet 2003 features an implementation field wider for SIA, and adds for its role as an information instrument of the approval process of development projects, which would allow, for example, the incorporation of principles connected to wider questions as human rights, democracy and valorization of the local knowledge.

It shows an effort of the international committee to start to have values and principles as a base, related not only to elements of applied order, but also to principles related to conceptual fundamentals that support the instrument. According to [21], "only by first establishing the core values of the community of practice, then deriving the principles, and only then developing guidelines, can truly appropriate guidelines emerge" (p. 1).

\section{Social Impacts Assessment in Brazil: Context and Practice}

\subsection{The Context in Brazil}

In Brazil, EIA is applied in a formal manner linked to the environmental licensing, which, by its turn, aims at the verification of the environmental feasibility of 
development projects (whether governmental or private) which have the potential to result in a relevant environmental degradation. The socio-economic environment integrates the impacts assessment on the Brazilian system, which means that it should condition the scope of the environmental studies and integrate the environmental baseline used to identify and assess the impacts. Conceptually, the information on the needs, aspirations and lifestyles of populations involved must be searched, to look for the comprehension of the consequences about the places affected with the implementation of the development to guide decisionmaking processes.

Regulation n. 01/1986 of the National Environment Council (CONAMA) establishes guidelines for the elaboration of Environmental Impact Statements (EIS) and the analysis of the environmental feasibility of development projects. In the first article, the regulation considers the environmental impact as the changes performed in physical, chemical or biological properties resulted from human activities, which may affect: the health, safety and welfare of the populations, the social and economic activities; the biota; aesthetic and sanitary conditions of the environment; and the quality of the natural resources.

In the $6^{\text {th }}$ article of the cited Regulation, it is set out that the environmental baseline must include physical, biological and socioeconomic aspects:

Art. 6th-The Environmental Impact Statement shall include, at minimum, the following technical activities:

1) Environmental baseline considering the project's area of influence, completely describing and analyzing of environmental resources and their interactions, as they are, in order to characterize the situation before project's implementation, including.

a) physical environment-subsoil, water, air and climate, focusing on mineral resources, topography, soils, hydrologic aspects, marine streams, atmospheric streams;

b) biological environment-fauna, flora, focusing on the species that are indicators of environmental quality, of scientific and economic value, rare and threatened, and protected areas,

c) socioeconomic environment-land usel cover, water uses and socio-economy, focusing on archeological, historical and cultural sites and monuments, dependency between local communities, environmental resources and their potential use in the future.

This legal requirement, associated to the verification of the project compatibility with the sectoral politics, plans and governmental programs purposed for the influence area of the project, set out by Article $5^{\text {th }}$ as one of the guidelines of the environmental impact studies, composes what the authors of the work herein consider as the fundamentals for the use of SIA in the country, integrated to EIA procedures.

The latest experience of the impact evaluation related to development projects (and mainly to what the federal government has been calling as "structuring projects", such as huge infrastructure works for the generation of energy, trans- 
ports, habitation and sanitation) has been showing a chronic deficiency in EIA practiced in the country, which the time for the decision making is extended due to the occurrence of intense conflicts and lawsuits. It is not wrong to affirm that the negative effects of this deficiency are increasing, mainly due to the difficulties to properly incorporate the social impact analysis in the decision process in regard to the approval of projects.

Yet it is possible to point for a reduction of the general gap described by [22] between EIA procedures and practice, and also a reduction of specific deficiencies in follow-up practice as pointed for [23], there are still several limitations associated to Environmental Impact Assessment in Brazil, which is less efficient in relation to the compliance with the role as a support element to the decision making.

\subsection{The Integration of Social Impacts in the Practice of EIA in Brazil}

The initial premise adopted in this paper relates to the systematic deficiency on the assessment of social impact in the country, thus agreeing with the conclusions of [5] about the secondary role played by SIA in impact assessment processes. In this sense, two main aspects were analyzed: the amplitude of the social variables employed for the description of the socioeconomic baseline in environmental impact studies in Brazil, and in relation to the international principles and guidelines and the SIA practice in the country.

Regarding the first aspect, a sample of 23 environmental impact statements (EIS) produced in the country was randomly selected. For each study, the variables associated to the socio-economic environment were identified, used for the creation of baseline, assuming that they will be-at least conceptually-associated to the evaluation of social impacts resulted from the project in analysis.

It were analyzed seven EIS coming from the federal level and sixteen from the state level, of different types of activity (Table 4): two studies for hydroelectric power plants $(\mathrm{H} 1, \mathrm{H} 2)$; two for thermoelectric $(\mathrm{T} 1, \mathrm{~T} 2)$; one for a small hydroelectric plant (SHP1); one for a reservoir (Res1); one for a transmission power line (Po); three for highways/roads (R1, R2, R3); one for housing (Hou1); three for landfills (L1, L2, L3); one for a sewage treatment plant (S1); one for an airport (A1); two for pipelines (P1, P2); two for industries (I1, I2); and three for ethanol production plants (E1, E2, E3).

Considering the set of variables employed in the baseline delimitation for the impact assessment on the socio-economic environment, it must be checked if they strict follow the scope defined by the federal legislation (even though, the legislation only indicates a basic guideline for the accomplishment of diagnostics for the socio-economic environment, which must be added in function for the specificities of each case). In addition, for the analyzed sample, it is not clear that there is a convergency among the variables employed in different impact studies, suggesting a weak learning among the studies. 
M. Montaño et al.

Table 4. Socioeconomic baseline variables applied in 23 EIS in Brazil.

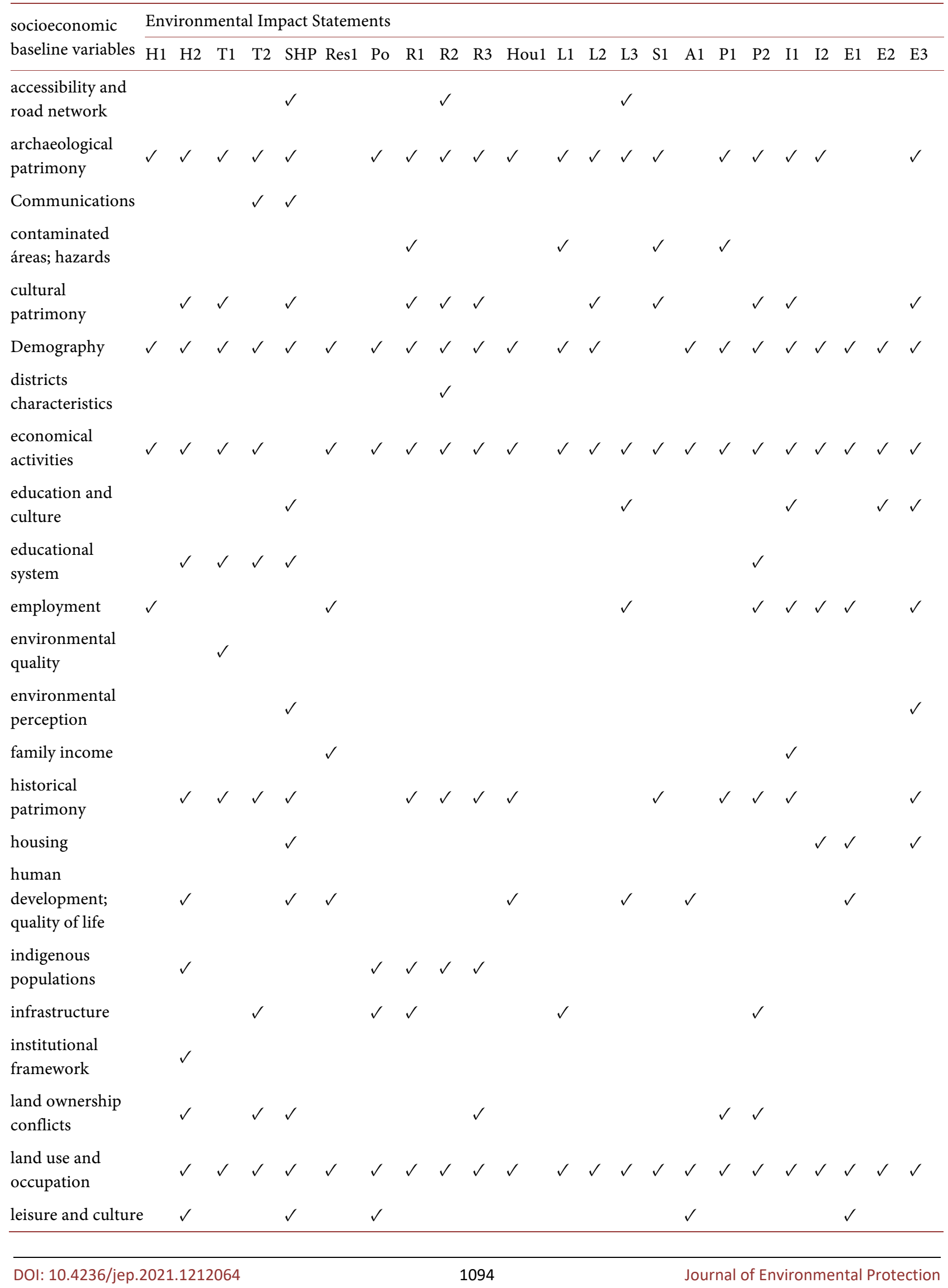


M. Montaño et al.

Continued

life conditions

local communities

organization

management and planning

mining rights

natural patrimony

protected areas

public finances

public goods

public health

public perception

regional

development

resettlements

road accidents

road

infrastructure

safety

sanitation

social and

economical

indicators

social equipments;

infrastructure

social

organization

social

responsibility

strategic

development

policies

territorial

organization

tourism

traditional

communities

transport

infrastructure

urban structure

and services

zoning $\checkmark$

$\checkmark$

$\begin{array}{llll}\checkmark & \checkmark & \checkmark & \checkmark\end{array}$

$\checkmark \checkmark$

$\checkmark$

$\checkmark$

$\checkmark$

$\begin{array}{ll}\checkmark & \checkmark \\ \checkmark & \checkmark\end{array}$

$\begin{array}{llll}\checkmark & \checkmark & \checkmark & \checkmark \\ \checkmark & & & \checkmark\end{array}$

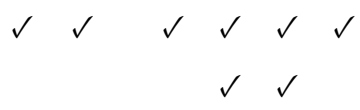

$\checkmark \quad \checkmark$

$\checkmark$

$\checkmark$

$\begin{array}{llllll}\checkmark & \checkmark & \checkmark & \checkmark & \checkmark & \checkmark\end{array}$

$\checkmark \quad \checkmark \quad \checkmark \quad \checkmark$

$\checkmark \quad \checkmark$

$\checkmark \begin{array}{lllll}\checkmark & \checkmark & \checkmark & \checkmark & \checkmark\end{array}$

$\checkmark$

$\checkmark$

$\checkmark$

$\checkmark$

$\checkmark$

$\checkmark$

$\checkmark$

$\checkmark$

$\checkmark \quad \checkmark$

$\checkmark$

$\checkmark \quad \checkmark$

$\checkmark$

DOI: 10.4236/jep.2021.1212064

1095

Journal of Environmental Protection 
Altogether, it is possible to affirm that the set of social variables employed in the baseline delimitation allows contemplating the scope set by the main referentes for the accomplishment of SIA. However, it is required a qualitative assessment of the social impact assessments to verify the integration level of the international principles and guidelines for SIA practice in Brazilian studies.

Accordingly, the analysis of seven Environmental Impact Studies (two federal and five state) were carried out, aiming to verify, from the relationship between the key elements of an EIA (baseline, impact prediction, mitigation and monitoring), the adhesion level between the universe of variables used in the baseline and impact assessment. What we see is a dramatic decrease from the universe of descriptive variables used in the baseline and social impacts identified and considered in impact assessments, as well as an extremely high variability regarding the incorporation of international principles and guidelines, which reinforces the need of formal adoption in Brazil, references to the achievement of the SIA.

Table 5 below presents the results of this procedure. You can check that, whatever is the reference adopted, the assessments carried out in Brazil do not contemplate-or only contemplate partially_important elements associated with the principles and guidelines recommended.

In any event involving the impacts assessment, there is a very clear dependency between the baseline and the quality of assessments. In the case of SIA applied in Brazil, this relationship is especially reflected in a low level of incorporation of international principles and guidelines, especially those that relate to important elements of SIA, such as adopted methodological aspects, data quality, identification of affected groups and equity of impacts, cumulative effects, proposing of mitigation measures and monitoring, and it has a particular relationship with the scope of the SIA itself as a promoting instrument of justice and environmental and social sustainability.

Many impacts considered in the study are characterized as processes of social change, such as changes in migration flows. This process will lead to other possible impacts such as disordered use of soil and increased demand for public services, which accumulate and interact. Therefore, there is a need to be raised all the possible effects of higher order and also the verification of its cumulativeness and synergy.

Understanding the diversity of social groups involved and affected by the implementation of the project is essential to work on issues related to vulnerability and equality before the impacts that will be caused. Surveys which express distributions of socio-cultural, ethnic, racial, gender, diversity, among others, provide a fair evaluation of the impacts of these different social groups, and allows the identification of vulnerable social actors and under-represented and to consider their local experiences and different cultural values of the evaluation.

The documents evaluated are systematically deficient in this regard, especially when concerning to the local population. Note that the demographic and economic data make it impossible to obtain the generic profile of this population, and it is necessary to use local scale surveys to understand processes relevant to 
Table 5. Principles and guidelines for SIA practice in seven studies carried out in Brazil.

\begin{tabular}{|c|c|c|c|c|c|c|c|c|}
\hline & & Hydro1 & Reserv1 & Road1 & Hous1 & Land1 & Sewage1 & Ind 1 \\
\hline & 1 & \pm & + & \pm & - & + & + & - \\
\hline & 2 & - & \pm & - & - & + & + & - \\
\hline & 3 & + & $\varnothing$ & + & \pm & + & + & - \\
\hline & 4 & + & + & - & \pm & \pm & $\varnothing$ & \pm \\
\hline \multirow[t]{13}{*}{ G\&P SIA } & 5 & \pm & - & - & - & + & + & \pm \\
\hline & 6 & + & + & + & \pm & + & - & $\varnothing$ \\
\hline & 7 & - & \pm & \pm & - & \pm & + & - \\
\hline & 8 & + & + & \pm & \pm & + & + & \pm \\
\hline & 9 & + & \pm & - & - & - & - & - \\
\hline & $1 \mathrm{a}$ & \pm & + & \pm & \pm & + & + & \pm \\
\hline & $1 b$ & - & \pm & + & \pm & + & \pm & \pm \\
\hline & $2 \mathrm{a}$ & \pm & \pm & \pm & - & + & \pm & - \\
\hline & $2 b$ & - & - & \pm & - & \pm & \pm & - \\
\hline & $3 a$ & - & - & $\varnothing$ & \pm & \pm & - & $\varnothing$ \\
\hline & $3 b$ & - & \pm & - & - & \pm & \pm & - \\
\hline & $3 c$ & - & \pm & - & - & + & - & \pm \\
\hline & $3 d$ & \pm & \pm & \pm & - & + & + & $\varnothing$ \\
\hline \multirow[t]{14}{*}{ US 2003} & $4 \mathrm{a}$ & - & \pm & - & \pm & + & \pm & + \\
\hline & $4 b$ & - & - & $\varnothing$ & \pm & \pm & $\varnothing$ & \pm \\
\hline & $4 c$ & \pm & $\varnothing$ & + & $\varnothing$ & \pm & + & \pm \\
\hline & $4 \mathrm{~d}$ & - & \pm & \pm & - & - & - & - \\
\hline & $5 a$ & - & \pm & \pm & - & + & \pm & - \\
\hline & $5 b$ & \pm & + & + & - & + & + & \pm \\
\hline & $6 \mathrm{a}$ & - & - & \pm & - & \pm & \pm & $\varnothing$ \\
\hline & $6 b$ & - & \pm & \pm & \pm & - & \pm & - \\
\hline & $6 c$ & + & \pm & - & - & - & - & - \\
\hline & 1 & - & \pm & - & - & + & + & - \\
\hline & 2 & $\mathrm{n} / \mathrm{a}$ & $\mathrm{n} / \mathrm{a}$ & $\mathrm{n} / \mathrm{a}$ & $\mathrm{n} / \mathrm{a}$ & $\mathrm{n} / \mathrm{a}$ & $\mathrm{n} / \mathrm{a}$ & $\mathrm{n} / \mathrm{a}$ \\
\hline & 3 & \pm & - & - & - & + & + & + \\
\hline & 4 & - & \pm & \pm & \pm & + & + & - \\
\hline & 5 & - & - & - & - & - & - & - \\
\hline \multirow{7}{*}{$\begin{array}{l}\text { INTERN 2003/SIA } \\
\text { principles }\end{array}$} & 6 & \pm & - & - & - & \pm & - & - \\
\hline & 7 & \pm & \pm & - & - & - & \pm & - \\
\hline & 8 & - & - & - & - & + & + & - \\
\hline & 9 & - & \pm & \pm & \pm & - & \pm & - \\
\hline & 10 & - & \pm & \pm & - & \pm & - & - \\
\hline & 11 & - & \pm & \pm & + & + & \pm & + \\
\hline & 12 & - & - & - & + & + & + & + \\
\hline
\end{tabular}

+: ok; Ø: not informed; -: not ok; n/a: not applied; \pm : partially. 
the assessment of impacts, particularly related to religious events, arts and cultural linked to population and that indicate attachment relationships with the environment.

In general, the analyzed EIS involve a poor level of lifestyle knowledge of sociocultural communities and individuals and their inter-community networks. Most diagnoses of local communities, for example, do not express the knowledge of their peculiar ways of sociocultural and economic organizing and territorial appropriation, covering just the important characteristics that would allow to understand the dependency relationships between the community and environmental resources.

There is a recurrent scarcity of data regarding community associations, interested groups, NGOs, social movements and other civil society associations. It is noticed that some EIS even raise the county associations, but without explicit relationship with other surveys along the study, which limits its contribution as an element for the assessment of impacts.

Among the impacts identified in the EIS, those related to expectations and insecurities triggered by population in employment generation during the implementation are invariably identified. Some studies also identify the expectations of attracting migrants during the operation of the project, depending on the type. The generation of skilled manpower for implementation always generates this workforce after completion of constructions, but some projects, such as dam, require large contingent during implementation and then, during operation, only few technicians are required. However, few projects propose measures to mitigate these impacts satisfactorily.

All of the analyzed EIS presented Social Communication Programs focused on the mitigation of the effects on the general expectations of communities and populations. On the few moments within EIA when community's perception is taken into account the mitigation proposal relies over an offer of information about the activity or project, which is much more to convince affected populations of the benefits that will come from project's implementation.

As described by [5], it is possible to mention that SIA in Brazil also suffers from the "displacement by public involvement", though it is still little advanced with regard to the inclusion of public participation in policies planning and development projects-being restricted to collective participation in public hearings to discuss the results of environmental studies, or through other formally established channels (but they normally lack of representativeness and legitimacy, such as state and municipal councils of the environment, and the role of civil society organizations).

Although it is possible to recognize substantial improvements in an expressive number of development projects due to public participation, when there is no formally structured way-legal requirements and guidelines for its preparationfor the systematic application of SIA in impact assessments, the logic which would justify social participation as a mechanism for incorporating the social impacts is extremely difficult, and subject to a number of accidents. 


\section{Conclusions}

The outcomes point out to an important deficiency in impact assessments related to the weak link between diagnostic studies and the assessment of the impacts. This deficiency is even more evident when it is noted that the completion of the impacts analysis on the human environment in Brazil is not performed in a structured way, which implies in scattered and superficial assessments, basically associated with socioeconomic and demographic variables.

Therefore, it is a significant issue-on the one hand, the low capacity of the professionals responsible for the preparation of environmental impact studies to identify and incorporate the real dimension of the social and cultural aspects and, institutionally, low capacity, along subsequent stages of the Environmental Impact Assessment, to identify weaknesses of the social studies and require more consistent studies.

Consequently, the social impacts of development projects have been evaluated in a partial and unsatisfactory manner-contributing to the emergence of conflicts and lawsuits surrounding the approval of projects.

The Brazilian situation is worrying-EIA with low capacity to act beyond the limits of the projects, with difficulty for the inclusion of social impacts. The practice in this field, as seen in this paper, is strongly limited and restricted to superficial analyzes.

The trajectory of SIA in Brazil follows the procedure described by [24] and others-inclusion in the formal framework of EIA, absence of effective elements for regulation of methodological and applied aspects, consolidation of an instrumental view of the instrument (based on descriptive aspects and demographics and socioeconomic data) and non-compliance with concepts and international principles/academic research.

The need for improvements in the integration of the social dimension in the Environmental Impact Assessment aimed for projects got evidenced. Strengthening SIA as decision support element supported by proper principles and guidelines may ensure its adequate implementation and effectiveness.

\section{Conflicts of Interest}

The authors declare no conflicts of interest regarding the publication of this paper.

\section{References}

[1] Wood, C. (1995) Environmental Impact Assessment: A Comparative Review. Longman, Harlow.

[2] Barker, A. and Wood, C. (1999) An Evaluation of EIA System Performance in Eight EU Countries. Environmental Impact Assessment Review, 19, 387-404. https://doi.org/10.1016/S0195-9255(99)00015-3

[3] Morgan, R.K. (2012) Environmental Impact Assessment: The State of the Art. Impact Assessment and Project Appraisal, 30, 5-14. https://doi.org/10.1080/14615517.2012.661557 
[4] Becker, H.A. (1997) Social Impact Assessment. UCL Press, London.

[5] Burdge, R.J. (2002) Why Is Social Impact Assessment the Orphan of the Assessment Process? Impact Assessment and Project Appraisal, 20, 3-9. https://doi.org/10.3152/147154602781766799

[6] Vanclay, F. (2003) Conceptual and Methodological Advances in Social Impact Assessment. In: Becker, H.A. and Vanclay, F., Eds., The International Handbook on Social Impact Assessment: Conceptual and Methodological Advances, Edward Elgar Publishing, Cheltenham.

[7] Barrow, C.J. (2004) Environmental Management and Sustainable Development. 2nd Edition, Routledge, Abingdon.

[8] Esteves, A.M., Franks, D. and Vanclay, F. (2012) Social Impact Assessment: The State of the Art. Impact Assessment and Project Appraisal, 30, 34-42. https://doi.org/10.1080/14615517.2012.660356

[9] Barrow, C.J. (2010) How Is Environmental Conflict Addressed by SIA? Environmental Impact Assessment Review, 30, 293-201.

https://doi.org/10.1016/j.eiar.2010.04.001

[10] Richardson, T. (2005) Environmental Assessment and Planning Theory: Four Short Stories about Power, Multiple Rationality, and Ethics. Environmental Impact Assessment Review, 25, 341-365. https://doi.org/10.1016/j.eiar.2004.09.006

[11] Doelle, M. and Sinclair, A.J. (2006) Time for a New Approach to Public Participation in EA: Promoting Cooperation and Consensus for Sustainability. Environmental Impact Assessment Review, 26, 185-205. https://doi.org/10.1016/j.eiar.2005.07.013

[12] Hanna, P., Vanclay, F., Langdon, E.J. and Arts, J. (2014) Improving the Effectiveness of Impact Assessment Pertaining to Indigenous Peoples in the Brazilian Environmental Licensing Procedure. Environmental Impact Assessment Review, 46, 58-67. https://doi.org/10.1016/j.eiar.2014.01.005

[13] Cashmore, M., Bond, A. and Sadler, B. (2009) Introduction: The Effectiveness of Impact Assessment Instruments. Impact Assessment and Project Appraisal, 27, 91-93. https://doi.org/10.3152/146155109X454285

[14] Therivel, R., Christian, G., Craig, C., Grinham, R., Mackins, D., Smith, S., Sneller, T., Turner, R., Walker, D. and Yamane, M. (2009) Sustainability-Focused Impact Assessment: English Experiences. Impact Assessment and Project Appraisal, 27, 155-168. https://doi.org/10.3152/146155109X438733

[15] Vanclay, F. (2002) Conceptualising Social Impacts. Environmental Impact Assessment Review, 22, 183-211. https://doi.org/10.1016/S0195-9255(01)00105-6

[16] Carpenter, R.A. (1999) Keep EIA Focused. Environmental Impact Assessment Review, 19, 111-112. https://doi.org/10.1016/S0195-9255(98)00044-4

[17] Vanclay, F. (2003) International Principles for Social Impact Assessment. Impact Assessment and Project Appraisal, 21, 5-11. https://doi.org/10.3152/147154603781766491

[18] Interorganizational Committee on Guidelines and Principles for Social Impact Assessment (1995) Guidelines and Principles for Social Impact Assessment. Environmental Impact Assessment Review, 15, 11-43. https://doi.org/10.1016/0195-9255(94)00026-W

[19] Vanclay, F. (2006) Principles for Social Impact Assessment: A Critical Comparison between the International and US Documents. Environmental Impact Assessment Review, 26, 3-14. https://doi.org/10.1016/j.eiar.2005.05.002 
[20] Interorganizational Comitee on Guidelines and Principles for Social Impact Assessment (2003) Principles and Guidelines for Social Impact Assessment in the USA. Impact Assessment and Project Appraisal, 21, 231-250. https://doi.org/10.3152/147154603781766293

[21] International Association for Impact Assessment (2003) International Principles for Social Impact Assessment. IAIA Special Publication Series, No. 2.

[22] Glasson, J. and Salvador, N.N.B. (2000) EIA in Brazil: A Procedures-Practice Gap. A Comparative Study with Reference to the European Union, and Especially the UK. Environmental Impact Assessment Review, 20,191-225. https://doi.org/10.1016/S0195-9255(99)00043-8

[23] Gallardo, A.L.C.F. and Sánchez, L.E. (2004) Follow-Up of a Road Building Scheme in a Fragile Environment. Environmental Impact Assessment Review, 24, 47-58. https://doi.org/10.1016/S0195-9255(03)00136-7

[24] Burdge, R.J. (2003) Benefiting from the Practice of Social Impact Assessment. Impact Assessment and Project Appraisal, 21, 225-229. https://doi.org/10.3152/147154603781766284 